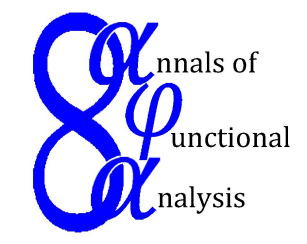

Ann. Funct. Anal. 6 (2015), no. 1, 235-248

http://doi.org/10.15352/afa/06-1-18

ISSN: 2008-8752 (electronic)

http://projecteuclid.org/afa

\title{
ON AN ITERATION PROCESS FOR COMMON FIXED POINTS OF NONSELF TOTAL ASYMPTOTICALLY NONEXPANSIVE MAPPINGS IN BANACH SPACES
}

\author{
SAFEER HUSSAIN KHAN ${ }^{1}$, HUKMI KIZILTUNC ${ }^{2 *}$ AND YUNUS PURTAS ${ }^{3}$ \\ Communicated by M. A. J. Pineda
}

\begin{abstract}
In this paper, we prove some weak and strong convergence results for a generalized three-step-three-mappings iteration scheme using a more satisfactory definition of nonself mappings. Our results approximate common fixed points of three nonself total asymptotically nonexpansive mappings in a uniformly convex Banach space.
\end{abstract}

\section{INTRODUCTION AND PRELIMINARIES}

Let $E$ be a real normed space, $K$ a nonempty subset of $E$ and $T: K \rightarrow K$ a mapping. Denote by $F(T)$ the set of fixed points of $T$, that is, $F(T)=\{x \in$ $K: T x=x\}$ and assume that $F(T) \neq \emptyset$. Throughout this paper, $\mathbb{N}$ denotes the set of positive integers. A mapping $T: K \rightarrow K$ is called asymptotically nonexpansive if there exists a sequence $\left\{k_{n}\right\} \subset[1, \infty)$ with $k_{n} \rightarrow 1$ such that $\left\|T^{n} x-T^{n} y\right\| \leq k_{n}\|x-y\|$ for all $x, y \in K$ and $n \in \mathbb{N}$. Goebel and Kirk [4] proved that if $K$ is a nonempty closed and bounded subset of a uniformly convex Banach space, then every asymptotically nonexpansive self-mapping has a fixed point.

Definition 1.1. [1]Let $K$ be a nonempty closed subset of a real normed linear space $E$. A mapping $T: K \rightarrow K$ is called total asymptotically nonexpansive if there exist nonnegative real sequences $\left\{\mu_{n}\right\},\left\{l_{n}\right\}$ with $\mu_{n}, l_{n} \rightarrow 0$ as $n \rightarrow \infty$ and

Date: Received: Jul. 14, 2013; Revised: Oct. 9, 2013; Accepted: Jan. 7, 2014.

* Corresponding author.

2010 Mathematics Subject Classification. Primary 47J05; Secondary 47H09, $47 \mathrm{H} 10$.

Key words and phrases. Nonself total asymptotically, strong and weak convergence, common fixed point, uniformly convex Banach spaces. 
a strictly increasing continuous function $\phi: \mathbb{R}^{+} \rightarrow \mathbb{R}^{+}$with $\phi(0)=0$ such that

$$
\left\|T^{n} x-T^{n} y\right\| \leq\|x-y\|+\mu_{n} \phi(\|x-y\|)+l_{n}, \quad n \in \mathbb{N}
$$

for all $x, y \in K$.

Remark 1.2. If $\phi(\lambda)=\lambda$, then (1.1) reduces to

$$
\left\|T^{n} x-T^{n} y\right\| \leq\left(1+\mu_{n}\right)\|x-y\|+l_{n}, \quad n \in \mathbb{N} .
$$

If $\phi(\lambda)=\lambda, l_{n}=0$ for all $n \in \mathbb{N}$, then a total asymptotically nonexpansive mapping becomes an asymptotically nonexpansive mapping. If we put $\mu_{n}=0$ and $l_{n}=0$ in (1.1)for all $n \in \mathbb{N}$, then we have the class of nonexpansive mappings.

The notion of total asymptotically nonexpansive mappings was introduced by Alber et al. [1]. They proved some strong and weak convergence results for this kind of mappings. Mukhamedov and Saburov [8] studied strong convergence of an explicit iteration process involving totally asymptotically $I$-nonexpansive mappings in Banach spaces. Chidume and Ofoedu [2] studied families of nonself total asymptotically nonexpansive mappings.

A subset $K$ of $E$ is said to be a retract if there exists a continuous mapping $P: E \rightarrow K$ such that $P x=x$ for all $x \in K$. Every closed convex subset of a uniformly convex Banach space is a retract. A mapping $P: E \rightarrow E$ is said to be a retraction if $P^{2}=P$. Let $P: E \rightarrow K$ be a nonexpansive retraction of $E$ into $K$. A nonself mapping $T: K \rightarrow E$ is called nonself asymptotically nonexpansive if for a sequence $\left\{k_{n}\right\} \subset[1, \infty)$ with $\lim _{n \rightarrow \infty} k_{n}=1$, we have $\left\|T(P T)^{n-1} x-T(P T)^{n-1} y\right\| \leq k_{n}\|x-y\|$ for all $x, y \in K$ and $n \in \mathbb{N}$. Khan and Hussain [6] studied the convergence for nonself asymptotically nonexpansive mappings in Banach spaces. Chidume et al. [3] established demiclosedness principle and gave strong and weak convergence results for such mappings in uniformly convex Banach spaces.

As a generalization of asymptotically nonexpansive nonself mappings, we introduce the following class of nonself total asymptotically nonexpansive mappings

Definition 1.3. [2]Let $K$ be a nonempty closed and convex subset of a real normed linear space $E$. Let $P: E \rightarrow K$ be a nonexpansive retraction of $E$ onto $K$. A nonself map $T: K \rightarrow E$ is said to be total asymptotically nonexpansive if there exist nonnegative real sequences $\left\{\mu_{n}\right\},\left\{l_{n}\right\}$ with $\mu_{n}, l_{n} \rightarrow 0$ as $n \rightarrow \infty$ and a strictly increasing continuous function $\phi: \mathbb{R}^{+} \rightarrow \mathbb{R}^{+}$with $\phi(0)=0$ such that

$$
\left\|T(P T)^{n-1} x-T(P T)^{n-1} y\right\| \leq\|x-y\|+\mu_{n} \phi(\|x-y\|)+l_{n}, \quad n \in \mathbb{N}
$$

for all $x, y \in K$.

Remark 1.4. If $\phi(\lambda)=\lambda$, then (1.2) reduces to

$$
\left\|T(P T)^{n-1} x-T(P T)^{n-1} y\right\| \leq\left(1+\mu_{n}\right)\|x-y\|+l_{n}, \quad n \in \mathbb{N} .
$$

A nonself total asymptotically nonexpansive mapping becomes

- a nonself asymptotically nonexpansive mapping if $\phi(\lambda)=\lambda, l_{n}=0$ for all $n \in \mathbb{N}$

- a nonself nonexpansive mapping if $\mu_{n}=0$ and $l_{n}=0$ for all $n \in \mathbb{N}$. 
As a matter of fact, if $T$ is a self-mapping, then $P$ is an identity mapping. In addition, if $T: K \rightarrow E$ is asymptotically nonexpansive and $P: E \rightarrow K$ is a nonexpansive retraction, then $P T: K \rightarrow K$ is asymptotically nonexpansive. Indeed, for all $x, y \in K$ and $n \in \mathbb{N}$, it follows that

$$
\begin{aligned}
\left\|(P T)^{n} x-(P T)^{n} y\right\| & =\left\|P T(P T)^{n-1} x-P T(P T)^{n-1} y\right\| \\
& \leq\left\|T(P T)^{n-1} x-T(P T)^{n-1} y\right\| \\
& \leq\|x-y\|+\mu_{n} \phi(\|x-y\|)+l_{n} .
\end{aligned}
$$

Thus a more satisfactory definition of a nonself total asymptotically nonexpansive mapping is as follows.

Definition 1.5. Let $K$ be a nonempty subset of real normed linear space $E$. Let $P: E \rightarrow K$ be a nonexpansive retraction of $E$ into $K$. A nonself mapping $T: K \rightarrow E$ is called total asymptotically nonexpansive with respect to $P$ if there exist nonnegative real sequences $\left\{\mu_{n}\right\},\left\{l_{n}\right\}$ with $\mu_{n}, l_{n} \rightarrow 0$ as $n \rightarrow \infty$ and a strictly increasing continuous function $\phi: \mathbb{R}^{+} \rightarrow \mathbb{R}^{+}$with $\phi(0)=0$ such that for all $x, y \in K$,

$$
\left\|(P T)^{n} x-(P T)^{n} y\right\| \leq\|x-y\|+\mu_{n} \phi(\|x-y\|)+l_{n}, \quad n \in \mathbb{N} .
$$

Proposition 1.6. Let $K$ be a nonempty subset of $E$ which is also a nonexpansive retract of a real normed linear space $E$ and let $\left\{T_{i}\right\}_{i=1}^{3}: K \rightarrow E$ be three nonself total asymptotically nonexpansive mappings. Then there exist nonnegative real sequences $\left\{\mu_{n}\right\}$ and $\left\{l_{n}\right\}, n \in \mathbb{N}$ with $\mu_{n}, l_{n} \rightarrow 0$ as $n \rightarrow \infty$ and strictly increasing continuous function $\phi: \mathbb{R}^{+} \rightarrow \mathbb{R}^{+}$with $\phi(0)=0$ such that

$$
\left\|\left(P T_{i}\right)^{n} x-\left(P T_{i}\right)^{n} y\right\| \leq\|x-y\|+\mu_{n} \phi(\|x-y\|)+l_{n}, \quad n \in \mathbb{N}
$$

for all $x, y \in K$ and each $i=1,2,3$.

Proof. Since $T_{i}: K \rightarrow E$ is a nonself total asymptotically nonexpansive mappings for each $i=1,2,3$, there exist nonnegative real sequences $\left\{\mu_{i n}\right\},\left\{l_{i n}\right\}, n \geq 1$ with $\mu_{\text {in }}, l_{\text {in }} \rightarrow 0$ as $n \rightarrow \infty$ and strictly increasing continuous function $\phi_{i}: \mathbb{R}^{+} \rightarrow \mathbb{R}^{+}$ with $\phi_{i}(0)=0$ such that for all $x, y \in K$,

$$
\left\|\left(P T_{i}\right)^{n} x-\left(P T_{i}\right)^{n} y\right\| \leq\|x-y\|+\mu_{i n} \phi_{i}(\|x-y\|)+l_{\text {in }}, \quad n \in \mathbb{N} .
$$

Setting

$$
\begin{aligned}
\mu_{n} & =\max \left\{\mu_{1 n}, \mu_{2 n}, \mu_{3 n}\right\}, \quad l_{n}=\max \left\{l_{1 n}, l_{2 n}, l_{3 n}\right\}, \\
\phi(a) & =\max \left\{\phi_{1}(a), \phi_{2}(a), \phi_{3}(a)\right\} \text { for } a \geq 0,
\end{aligned}
$$

we obtain nonnegative real sequences $\left\{\mu_{n}\right\}$ and $\left\{l_{n}\right\}, n \in \mathbb{N}$ with $\mu_{n}, l_{n} \rightarrow 0$ as $n \rightarrow \infty$ and strictly increasing continuous function $\phi: \mathbb{R}^{+} \rightarrow \mathbb{R}^{+}$with $\phi(0)=0$ such that

$$
\begin{aligned}
\left\|\left(P T_{i}\right)^{n} x-\left(P T_{i}\right)^{n} y\right\| & \leq\|x-y\|+\mu_{i n} \phi_{i}(\|x-y\|)+l_{\text {in }} \\
& \leq\|x-y\|+\mu_{n} \phi(\|x-y\|)+l_{n}, \quad n \in \mathbb{N},
\end{aligned}
$$

for all $x, y \in K$, and each $i=1,2,3$. 
In [5], strong convergence results for a modified three step iterative process in the setting of Banach spaces were proved. In 2011, Rashwan and Altwqi [9] approximated common fixed points of three nonself asymptotically nonexpansive mappings in a real uniformly convex Banach space using the following iteration scheme:

Let $K$ be a nonempty closed convex subset of a real uniformly convex Banach space $E$ which is also a nonexpansive retract of $E$. Let $T_{i}: K \rightarrow E(i=1,2,3)$ be three nonself asymptotically nonexpansive mappings with sequences $\mu_{n}, l_{n} \subset$ $[0, \infty)$ such that $\sum_{n=1}^{\infty} \mu_{n}<\infty, \sum_{n=1}^{\infty} l_{n}<\infty$. Then for a given $x_{1} \in K$,

$$
\left\{\begin{array}{ccc}
x_{n+1}= & P\left(\left(1-\alpha_{n}\right) y_{n}+\alpha_{n} T_{1}\left(P T_{1}\right)^{n-1} y_{n}\right) \\
y_{n}= & P\left(\left(1-\beta_{n}\right) z_{n}+\beta_{n} T_{2}\left(P T_{2}\right)^{n-1} z_{n}\right) \\
z_{n}= & P\left(\left(1-\gamma_{n}\right) x_{n}+\gamma_{n} T_{3}\left(P T_{3}\right)^{n-1} x_{n}\right), n \in \mathbb{N}
\end{array}\right.
$$

where $\left\{\alpha_{n}\right\},\left\{\beta_{n}\right\},\left\{\gamma_{n}\right\}$ are sequences in $[0,1]$.

If $\gamma_{n}=0$, then (1.5) reduces to the iteration scheme defined by Thianwan [1]] as follows:

$$
\left\{\begin{array}{l}
x_{n+1}=P\left(\left(1-\alpha_{n}\right) y_{n}+\alpha_{n} T_{1}\left(P T_{1}\right)^{n-1} y_{n}\right) \\
y_{n}=P\left(\left(1-\beta_{n}\right) x_{n}+\beta_{n} T_{2}\left(P T_{2}\right)^{n-1} x_{n}\right), n \in \mathbb{N}
\end{array}\right.
$$

where $\left\{\alpha_{n}\right\},\left\{\beta_{n}\right\}$ are sequences in $[0,1]$.

If $\gamma_{n}=0, \beta_{n}=0$, then (1.5) reduces to the iteration scheme defined by Chidume et al. [3] as follows:

$$
x_{n+1}=P\left(\left(1-\alpha_{n}\right) x_{n}+\alpha_{n} T(P T)^{n-1} x_{n}\right), n \in \mathbb{N},
$$

where $\left\{\alpha_{n}\right\}$ is a sequence in $[0,1]$.

In wake of the Definition (1.5), we study the following iteration scheme. Let $K$ be a nonempty closed convex subset of a real normed linear space $E$ with retraction $P$. Let $T_{i}: K \rightarrow E(i=1,2,3)$ be three nonself total asymptotically nonexpansive mappings with respect to $P$ and sequences $\mu_{n}, l_{n} \subset[0, \infty)$ such that $\sum_{n=1}^{\infty} \mu_{n}<\infty, \sum_{n=1}^{\infty} l_{n}<\infty$. Then for a given $x_{1} \in K$,

$$
\left\{\begin{array}{l}
x_{n+1}=\left(1-\alpha_{n}\right) y_{n}+\alpha_{n}\left(P T_{1}\right)^{n} y_{n} \\
y_{n}=\left(1-\beta_{n}\right) z_{n}+\beta_{n}\left(P T_{2}\right)^{n} z_{n} \\
z_{n}=\left(1-\gamma_{n}\right) x_{n}+\gamma_{n}\left(P T_{3}\right)^{n} x_{n}, n \in \mathbb{N}
\end{array}\right.
$$

where $\left\{\alpha_{n}\right\},\left\{\beta_{n}\right\},\left\{\gamma_{n}\right\}$ are sequences in $[0,1]$. Following the method of Rashwan and Altwqi [9], it is not difficult to see that our process is able to compute common fixed points at a rate better than (1.5). It is noteworthy that our iteration process is better than [9] because we use a better definition of nonself mappings.

In this paper, we study convergence of the iterative scheme (1.6) involving three total asymptotically nonexpansive mappings on a nonempty closed convex subset of a uniformly convex Banach space.

In the sequel, we need the following useful known concepts and lemmas in order to prove our main results. 
Let $E$ be a Banach space with dimension $E \geq 2$. The modulus of $E$ is the function $\delta_{E}:(0,2] \rightarrow[0,1]$ defined by

$$
\delta_{E}(\varepsilon)=\inf \left\{1-\left\|\frac{1}{2}(x+y)\right\|:\|x\|=1, \quad\|y\|=1, \quad \varepsilon=\|x-y\|\right\} .
$$

A Banach space $E$ is uniformly convex if and only if $\delta_{E}(\varepsilon)>0$ for all $\varepsilon \in(0,2]$.

A Banach space $E$ is said to satisfy Opial's condition [12] if, for each sequence $\left\{x_{n}\right\}$ in $E$ such that $\left\{x_{n}\right\}$ converges weakly to $x$ implies that

$$
\limsup _{n \rightarrow \infty}\left\|x_{n}-x\right\|<\limsup _{n \rightarrow \infty}\left\|x_{n}-y\right\|
$$

for all $y \in E$ with $y \neq x$. It is well known that (see [7]) inequality (1.7) is equivalent to

$$
\lim _{n \rightarrow \infty} \sup \left\|x_{n}-x\right\|<\lim _{n \rightarrow \infty} \sup \left\|x_{n}-y\right\| .
$$

A family $\left\{T_{i}: i=1,2,3\right\}$ of three nonself mappings of $K$ with the set of common fixed points $\mathcal{F}=\bigcap_{i=1}^{3} F\left(T_{i}\right) \neq \emptyset$ is said to satisfy condition $(B)$ on $K$ if there is a nondecreasing function $f: \mathbb{R}^{+} \rightarrow \mathbb{R}^{+}$with $f(0)=0$ and $f(r)>0$ for all $r>0$ such that for all $x \in K$,

$$
\max _{1 \leq i \leq 3}\left\{\left\|x-T_{i} x\right\|\right\} \geq f(d(x, \mathcal{F})) .
$$

Definition 1.7. Let $K$ be a closed subset of a real Banach space $E$ and let $T$ : $K \rightarrow K$ be a mapping. $T$ is said to be demicompact, if for any bounded sequence $\left\{x_{n}\right\}$ in $K$ such that $\left\|x_{n}-T x_{n}\right\| \rightarrow 0$ as $n \rightarrow \infty$, there exists a subsequence $\left\{x_{n_{k}}\right\} \subset\left\{x_{n}\right\}$ such that $x_{n_{k}} \rightarrow x^{*} \in K$.

Definition 1.8. Let $K$ be a closed subset of a real Banach space $E$ and let $T: K \rightarrow K$ be a mapping. $T$ is said to be semiclosed (demiclosed) at zero, if for each bounded sequence $\left\{x_{n}\right\}$ in $K$, the conditions $x_{n}$ converges weakly to $x \in K$ and $T x_{n}$ converges strongly to 0 imply $T x=0$.

Lemma 1.9. [10] Let $\left\{a_{n}\right\},\left\{b_{n}\right\}$ and $\left\{c_{n}\right\}$ be sequences of nonnegative real numbers satisfying the inequality

$$
a_{n+1} \leq\left(1+b_{n}\right) a_{n}+c_{n}, \quad n \in \mathbb{N} .
$$

If $\sum_{n=1}^{\infty} c_{n}<\infty$ and $\sum_{n=1}^{\infty} b_{n}<\infty$, then

(i) $\lim _{n \rightarrow \infty} a_{n}$ exists;

(ii) In particular, if $\left\{a_{n}\right\}$ has a subsequence $\left\{a_{n_{k}}\right\}$ converging strongly to zero, then $\lim _{n \rightarrow \infty} a_{n}=0$.

Lemma 1.10. [13] Let $p>1$ and $D>0$ be two fixed real numbers. Then a Banach space $E$ is uniformly convex if and only if there is a continuous, strictly increasing and convex function $g: \mathbb{R}^{+} \rightarrow \mathbb{R}^{+}$, with $g(0)=0$ and

$$
\|\lambda x+(1-\lambda) y\|^{p} \leq \lambda\|x\|^{p}+(1-\lambda)\|y\|^{p}-w_{p}(\lambda) g(\|x-y\|)
$$

for all $x, y \in B_{D}$ and $0 \leq \lambda \leq 1$, where $B_{D}$ is the closed ball with center zero and radius $D, w_{p}(\lambda)=\lambda(1-\lambda)^{p}+\lambda^{p}(1-\lambda)$. 


\section{Main Results}

In this section, we prove some convergence results for the iteration scheme (1.6) for three nonself total asymptotically nonexpansive mappings in Banach spaces.

Throughout this paper, we denote by $\mathcal{F}:=\bigcap_{i=1}^{3} F\left(T_{i}\right)$, the set of common fixed points of $T_{1}, T_{2}, T_{3}$ and assume that $\mathcal{F}$ is singleton, In order to prove our main results, the following lemmas are needed.

Lemma 2.1. Let $K$ be a nonempty closed convex subset of a real Banach space $E$ which is also a nonexpansive retract of $E$ and $T_{1}, T_{2}, T_{3}: K \rightarrow E$ be three nonself total asymptotically nonexpansive mappings defined by (1.4) such that $\sum_{n=1}^{\infty} \mu_{n}<$ $\infty, \sum_{n=1}^{\infty} l_{n}<\infty$. Assume that there exist $M, M^{*}>0$ such that $\phi(\lambda) \leq M^{*} \lambda$ for all $\lambda \geq M$. Suppose that $\left\{x_{n}\right\}$ is defined by (1.6) and $\mathcal{F}$ is singleton. Then the sequence $\left\{x_{n}\right\}$ is bounded and for each $q \in \mathcal{F}, \lim _{n \rightarrow \infty}\left\|x_{n}-q\right\|$ exists.

Proof. Let $q \in \mathcal{F}$. Since $T_{3}$ is a nonself total asymptotically nonexpansive mapping, we have from (1.6) that

$$
\begin{aligned}
\left\|z_{n}-q\right\| & \leq\left(1-\gamma_{n}\right)\left\|x_{n}-q\right\|+\gamma_{n}\left\|\left(P T_{3}\right)^{n} x_{n}-q\right\| \\
& \leq\left(1-\gamma_{n}\right)\left\|x_{n}-q\right\|+\gamma_{n}\left[\left\|x_{n}-q\right\|+\mu_{n} \phi\left(\left\|x_{n}-q\right\|\right)+l_{n}\right] \\
& =\left\|x_{n}-q\right\|+\gamma_{n} \mu_{n} \phi\left(\left\|x_{n}-q\right\|\right)+\gamma_{n} l_{n}
\end{aligned}
$$

Since $\phi: \mathbb{R}^{+} \rightarrow \mathbb{R}^{+}$is a strictly increasing continuous function, it follows that $\phi(\lambda) \leq \phi(M)$ whenever $\lambda \leq M$. Moreover, by the hypothesis, $\phi(\lambda) \leq M^{*} \lambda$ for all $\lambda \geq M$. In either case, we have

$$
\phi(\lambda) \leq \phi(M)+M^{*} \lambda
$$

for some $M, M^{*}>0$. Thus from (2.1) and (2.2), we get

$$
\begin{aligned}
\left\|z_{n}-q\right\| & \leq\left\|x_{n}-q\right\|+\gamma_{n} \mu_{n}\left[\phi(M)+M^{*}\left\|x_{n}-q\right\|\right]+\gamma_{n} l_{n} \\
& =\left(1+M^{*} \gamma_{n} \mu_{n}\right)\left\|x_{n}-q\right\|+\phi(M) \gamma_{n} \mu_{n}+\gamma_{n} l_{n} \\
& \leq\left(1+M^{*} \phi(M) \mu_{n}\right)\left\|x_{n}-q\right\|+M^{*} \phi(M)\left(\mu_{n}+l_{n}\right) \\
& =\left(1+R_{1} \mu_{n}\right)\left\|x_{n}-q\right\|+R_{1}\left(\mu_{n}+l_{n}\right)
\end{aligned}
$$

where $R_{1}=M^{*} \phi(M)>0$.

Next,

$$
\begin{aligned}
\left\|y_{n}-q\right\| & \leq\left(1-\beta_{n}\right)\left\|z_{n}-q\right\|+\beta_{n}\left\|\left(P T_{2}\right)^{n} z_{n}-q\right\| \\
& \leq\left(1-\beta_{n}\right)\left\|z_{n}-q\right\|+\beta_{n}\left[\left\|z_{n}-q\right\|+\mu_{n} \phi\left(\left\|z_{n}-q\right\|\right)+l_{n}\right] \\
& \leq\left\|z_{n}-q\right\|+\beta_{n} \mu_{n}\left[\phi(M)+M^{*}\left\|z_{n}-q\right\|\right]+\beta_{n} l_{n} \\
& =\left(1+M^{*} \beta_{n} \mu_{n}\right)\left\|z_{n}-q\right\|+\phi(M) \beta_{n} \mu_{n}+\beta_{n} l_{n} \\
& \leq\left(1+M^{*} \phi(M) \mu_{n}\right)\left\|z_{n}-q\right\|+M^{*} \phi(M)\left(\mu_{n}+l_{n}\right) \\
& =\left(1+R_{1} \mu_{n}\right)\left\|z_{n}-q\right\|+R_{1}\left(\mu_{n}+l_{n}\right) .
\end{aligned}
$$


From (2.3) and (2.4), we get

$$
\begin{aligned}
\left\|y_{n}-q\right\| & \leq\left(1+R_{1} \mu_{n}\right)\left\|z_{n}-q\right\|+R_{1}\left(\mu_{n}+l_{n}\right) \\
& \leq\left(1+R_{1} \mu_{n}\right)\left[\left(1+R_{1} \mu_{n}\right)\left\|x_{n}-q\right\|+R_{1}\left(\mu_{n}+l_{n}\right)\right]+R_{1}\left(\mu_{n}+l_{n}\right) \\
& =\left[1+\left(2 R_{1}+R_{1}^{2} \mu_{n}\right) \mu_{n}\right]\left\|x_{n}-q\right\|+\left(2 R_{1}+R_{1}^{2} \mu_{n}\right)\left(\mu_{n}+l_{n}\right) \\
& =\left(1+R_{2} \mu_{n}\right)\left\|x_{n}-q\right\|+R_{2}\left(\mu_{n}+l_{n}\right)
\end{aligned}
$$

where $R_{2}=2 R_{1}+R_{1}^{2} \mu_{n}>0$.

Thus

$$
\begin{aligned}
\left\|x_{n+1}-q\right\| & \leq\left(1-\alpha_{n}\right)\left\|y_{n}-q\right\|+\alpha_{n}\left\|\left(P T_{1}\right)^{n} y_{n}-q\right\| \\
& \leq\left(1-\alpha_{n}\right)\left\|y_{n}-q\right\|+\alpha_{n}\left[\left\|y_{n}-q\right\|+\mu_{n} \phi\left(\left\|y_{n}-q\right\|\right)+l_{n}\right] \\
& \leq\left\|y_{n}-q\right\|+\alpha_{n} \mu_{n}\left[\phi(M)+M^{*}\left\|y_{n}-q\right\|\right]+\alpha_{n} l_{n} \\
& =\left(1+M^{*} \alpha_{n} \mu_{n}\right)\left\|y_{n}-q\right\|+\phi(M) \alpha_{n} \mu_{n}+\alpha_{n} l_{n} \\
& \leq\left(1+M^{*} \phi(M) \mu_{n}\right)\left\|y_{n}-q\right\|+M^{*} \phi(M)\left(\mu_{n}+l_{n}\right) \\
& =\left(1+R_{1} \mu_{n}\right)\left\|y_{n}-q\right\|+R_{1}\left(\mu_{n}+l_{n}\right) .
\end{aligned}
$$

From (2.5) and (2.6), we are able to write

$$
\begin{aligned}
\left\|x_{n+1}-q\right\| \leq & \left(1+R_{1} \mu_{n}\right)\left\|y_{n}-q\right\|+R_{1}\left(\mu_{n}+l_{n}\right) \\
\leq & \left(1+R_{1} \mu_{n}\right)\left[\left(1+R_{2} \mu_{n}\right)\left\|x_{n}-q\right\|+R_{2}\left(\mu_{n}+l_{n}\right)\right] \\
& +R_{1}\left(\mu_{n}+l_{n}\right) \\
= & \left(1+R_{1} \mu_{n}\right)\left(1+R_{2} \mu_{n}\right)\left\|x_{n}-q\right\| \\
& +\left(1+R_{1} \mu_{n}\right) R_{2}\left(\mu_{n}+l_{n}\right)+R_{1}\left(\mu_{n}+l_{n}\right) \\
= & {\left[1+\mu_{n}\left(R_{1}+R_{2}+R_{1} R_{2} \mu_{n}\right)\right]\left\|x_{n}-q\right\| } \\
& +\left(R_{1}+R_{2}+R_{1} R_{2} \mu_{n}\right)\left(\mu_{n}+l_{n}\right) \\
= & \left(1+R_{3} \mu_{n}\right)\left\|x_{n}-q\right\|+R_{3}\left(\mu_{n}+l_{n}\right)
\end{aligned}
$$

where $R_{3}=R_{1}+R_{2}+R_{1} R_{2} \mu_{n}>0$.

Since $\sum_{n=1}^{\infty} \mu_{n}<\infty$ and $\sum_{n=1}^{\infty} l_{n}<\infty$, by Lemma 1.9, we have $\lim _{n \rightarrow \infty}\left\|x_{n}-q\right\|$ exists.

Theorem 2.2. Let $K$ be a nonempty closed convex subset of a real Banach space $E$ which is also a nonexpansive retract of $E$ and $T_{1}, T_{2}, T_{3}: K \rightarrow E$ be three continuous nonself total asymptotically nonexpansive mappings defined by (1.4) such that $\sum_{n=1}^{\infty} \mu_{n}<\infty, \sum_{n=1}^{\infty} l_{n}<\infty$. Assume that there exist $M, M^{*}>0$ such that $\phi(\lambda) \leq M^{*} \lambda$ for all $\lambda \geq M$. Suppose that $\mathcal{F}$ is singleton. Then the sequence $\left\{x_{n}\right\}$ defined by (1.6) converges strongly to a common fixed point of $T_{1}, T_{2}, T_{3}$ if and only if $\liminf \operatorname{in}_{n \rightarrow \infty} d\left(x_{n}, \mathcal{F}\right)=0$, where $d(x, \mathcal{F})=\inf _{q \in \mathcal{F}}\left\|x_{n}-q\right\|, n \in \mathbb{N}$.

Proof. The necessity is obvious. Let us assume that $\liminf _{n \rightarrow \infty} d\left(x_{n}, \mathcal{F}\right)=0$ and prove that the sequence $\left\{x_{n}\right\}$ converges to a common fixed point of $T_{1}, T_{2}, T_{3}$. We first show that $\left\{x_{n}\right\}$ is a Cauchy sequence in $E$. Let $b_{n}=R_{3} \mu_{n}, c_{n}=$ $R_{3}\left(\mu_{n}+l_{n}\right)$.The inequality (2.7) combined with the fact $1+t \leq \exp (t)$ for all 
$t>0$ yields for all $m \in \mathbb{N}$

$$
\begin{aligned}
\left\|x_{n+m}-q\right\| \leq & \exp \left(b_{n+m-1}\right)\left(\left\|x_{n+m-1}-q\right\|+c_{n+m-1}\right) \\
& \vdots \\
\leq & \exp \left(\sum_{i=n}^{n+m-1} b_{i}\right)\left\|x_{n}-q\right\|+\left(\sum_{i=n}^{n+m-1} c_{i}\right) \exp \left(\sum_{i=n}^{n+m-1} b_{i}\right) \\
\leq & \exp \left(\sum_{i=n}^{\infty} b_{i}\right)\left\|x_{n}-q\right\|+\left(\sum_{i=n}^{\infty} c_{i}\right) \exp \left(\sum_{i=n}^{\infty} b_{i}\right) .
\end{aligned}
$$

Thus for all $m \in \mathbb{N}$ and $q \in \mathcal{F}$, we have

$$
\begin{aligned}
\left\|x_{n+m}-x_{n}\right\| & \leq\left\|x_{n+m}-q\right\|+\left\|x_{n}-q\right\| \\
& \leq\left(1+\exp \left(\sum_{i=n}^{\infty} b_{i}\right)\right)\left\|x_{n}-q\right\|+\exp \left(\sum_{i=n}^{\infty} b_{i}\right) \sum_{i=n}^{\infty} c_{i} \\
& \leq A\left(\left\|x_{n}-q\right\|+\sum_{i=n}^{\infty} c_{i}\right) \\
& \leq A\left(d\left(x_{n}, \mathcal{F}\right)+\sum_{i=n}^{\infty} c_{i}\right),
\end{aligned}
$$

where $0<A-1=\exp \left(\sum_{i=n}^{\infty} b_{i}\right)<\infty$. Since $\lim _{n \rightarrow \infty} d\left(x_{n}, \mathcal{F}\right)=0$ and $\sum_{i=1}^{\infty} c_{i}<$ $\infty$, given $\varepsilon>0$ there exists an integer $n_{0}>0$ such that for all $n>n_{0}$, we have $d\left(x_{n}, \mathcal{F}\right)<\frac{\varepsilon}{2 A}$ and $\sum_{i=n}^{\infty} c_{i}<\frac{\varepsilon}{2 A}$. Thus for all integers $n>n_{0}$ and $m \in \mathbb{N},(2.8)$ gives

$$
\left\|x_{n+m}-x_{n}\right\| \leq \varepsilon
$$

This means that $\left\{x_{n}\right\}$ is a Cauchy sequence in $E$. Completeness of $E$ now guarantees the existence of $x^{*} \in E$ such that $x_{n} \rightarrow x^{*}$.

Next, we show that $x^{*}$ is a common fixed point of $T_{1}, T_{2}, T_{3}$. Suppose that $x^{*} \notin \mathcal{F}$. Since $\mathcal{F}$ is closed subset of $E$, one has $d\left(x^{*}, \mathcal{F}\right)>0$. However, for all $q \in \mathcal{F}$, we have

$$
\left\|x^{*}-q\right\| \leq\left\|x_{n}-x^{*}\right\|+\left\|x_{n}-q\right\|
$$

This implies that

$$
d\left(x^{*}, \mathcal{F}\right) \leq\left\|x_{n}-x^{*}\right\|+d\left(x_{n}, \mathcal{F}\right) .
$$

Since $x_{n} \rightarrow x^{*}, d\left(x^{*}, \mathcal{F}\right)=0$ as $n \rightarrow \infty$.This contradicts $d\left(x^{*}, \mathcal{F}\right)>0$. Hence, $x^{*}$ is a common fixed point of $T_{1}, T_{2}, T_{3}$ as required.

Lemma 2.3. Let $K$ be a nonempty closed convex subset of a uniformly convex Banach space $E$ which is also a nonexpansive retract of $E$ and $T_{1}, T_{2}, T_{3}: K \rightarrow E$ be three nonself total asymptotically nonexpansive mappings defined by (1.4) such that $\sum_{n=1}^{\infty} \mu_{n}<\infty, \sum_{n=1}^{\infty} l_{n}<\infty$. Assume that there exist $M, M^{*}>0$ such that $\phi(\lambda) \leq M^{*} \lambda$ for all $\lambda \geq M$. Suppose that $\mathcal{F}$ is singleton and $\left\{\alpha_{n}\right\},\left\{\beta_{n}\right\},\left\{\gamma_{n}\right\}$ are sequences in $[0,1]$ which satisfy the following conditions:

(i) $0<\liminf _{n \rightarrow \infty} \alpha_{n}<\limsup _{n \rightarrow \infty} \alpha_{n}<1$

(ii) $0<\liminf _{n \rightarrow \infty} \beta_{n}<\limsup _{n \rightarrow \infty} \beta_{n}<1$ 
(iii) $0<\liminf _{n \rightarrow \infty} \gamma_{n}<\limsup _{n \rightarrow \infty} \gamma_{n}<1$.

Then $\lim _{n \rightarrow \infty}\left\|\left(P T_{i}\right)^{n} x_{n}-x_{n}\right\|=0$ for all $i=1,2,3$.

Proof. By Lemma 2.1, $\lim _{n \rightarrow \infty}\left\|x_{n}-q\right\|$ exists. Assume that, for $q \in \mathcal{F}, \lim _{n \rightarrow \infty}$ $\left\|x_{n}-q\right\|=r$. If $r=0$, the conclusion is obvious. Suppose $r>0$. Since $\left\{x_{n}-q\right\}$ is bounded, $\left\{z_{n}-q\right\}$ and $\left\{y_{n}-q\right\}$ are also bounded. As $T_{i}$ are nonself total asymptotically nonexpansive mappings, we can prove that the sequences $\left\{\left(P T_{1}\right)^{n} y_{n}-q\right\},\left\{\left(P T_{2}\right)^{n} z_{n}-q\right\},\left\{\left(P T_{3}\right)^{n} x_{n}-q\right\}$ are all bounded. Using (1.6) and Lemma 1.10, we have for some constant $D_{1}>0$ that

$$
\begin{aligned}
\left\|z_{n}-q\right\|^{2}= & \left\|\left(1-\gamma_{n}\right)\left(x_{n}-q\right)+\gamma_{n}\left(\left(P T_{3}\right)^{n} x_{n}-q\right)\right\|^{2} \\
\leq & \left(1-\gamma_{n}\right)\left\|x_{n}-q\right\|^{2}+\gamma_{n}\left\|\left(P T_{3}\right)^{n} x_{n}-q\right\|^{2} \\
& -\gamma_{n}\left(1-\gamma_{n}\right) g_{1}\left(\left\|x_{n}-\left(P T_{3}\right)^{n} x_{n}\right\|\right) \\
\leq & \left\|x_{n}-q\right\|^{2}+D_{1}\left(\mu_{n}+l_{n}\right) \\
& -\gamma_{n}\left(1-\gamma_{n}\right) g_{1}\left(\left\|x_{n}-\left(P T_{3}\right)^{n} x_{n}\right\|\right) .
\end{aligned}
$$

It follows from (1.6) and (2.9) that for some constant $D_{2}>0$,

$$
\begin{aligned}
\left\|y_{n}-q\right\|^{2}= & \left\|\left(1-\beta_{n}\right)\left(z_{n}-q\right)+\beta_{n}\left(\left(P T_{2}\right)^{n} z_{n}-q\right)\right\|^{2} \\
\leq & \left(1-\beta_{n}\right)\left\|z_{n}-q\right\|^{2}+\beta_{n}\left\|\left(P T_{2}\right)^{n} z_{n}-q\right\|^{2} \\
& -\beta_{n}\left(1-\beta_{n}\right) g_{2}\left(\left\|z_{n}-\left(P T_{2}\right)^{n} z_{n}\right\|\right) \\
\leq & \left\|x_{n}-q\right\|^{2}+D_{2}\left(\mu_{n}+l_{n}\right)-\gamma_{n}\left(1-\gamma_{n}\right) g_{1}\left(\left\|x_{n}-\left(P T_{3}\right)^{n} x_{n}\right\|\right) \\
& -\beta_{n}\left(1-\beta_{n}\right) g_{2}\left(\left\|z_{n}-\left(P T_{2}\right)^{n} z_{n}\right\|\right) .
\end{aligned}
$$

Similarly, from (1.6), (2.9) and (2.10), there is a constant $D_{3}>0$ such that

$$
\begin{aligned}
\left\|x_{n+1}-q\right\|^{2}= & \left\|\left(1-\alpha_{n}\right)\left(y_{n}-q\right)+\alpha_{n}\left(\left(P T_{1}\right)^{n} y_{n}-q\right)\right\|^{2} \\
\leq & \left(1-\alpha_{n}\right)\left\|y_{n}-q\right\|^{2}+\alpha_{n}\left\|\left(P T_{1}\right)^{n} y_{n}-q\right\|^{2} \\
& -\alpha_{n}\left(1-\alpha_{n}\right) g_{3}\left(\left\|y_{n}-\left(P T_{1}\right)^{n} y_{n}\right\|\right) \\
\leq & \left\|x_{n}-q\right\|^{2}+D_{3}\left(\mu_{n}+l_{n}\right)-\gamma_{n}\left(1-\gamma_{n}\right) g_{1}\left(\left\|x_{n}-\left(P T_{3}\right)^{n} x_{n}\right\|\right) \\
& -\beta_{n}\left(1-\beta_{n}\right) g_{2}\left(\left\|z_{n}-\left(P T_{2}\right)^{n} z_{n}\right\|\right) \\
& -\alpha_{n}\left(1-\alpha_{n}\right) g_{3}\left(\left\|y_{n}-\left(P T_{1}\right)^{n} y_{n}\right\|\right) .
\end{aligned}
$$

From (2.11), we can write

$$
\begin{aligned}
& \gamma_{n}\left(1-\gamma_{n}\right) g_{1}\left(\left\|x_{n}-\left(P T_{3}\right)^{n} x_{n}\right\|\right) \leq\left\|x_{n}-q\right\|^{2}-\left\|x_{n+1}-q\right\|^{2}+D_{3}\left(\mu_{n}+l_{n}\right), \\
& \beta_{n}\left(1-\beta_{n}\right) g_{2}\left(\left\|z_{n}-\left(P T_{2}\right)^{n} z_{n}\right\|\right) \leq\left\|x_{n}-q\right\|^{2}-\left\|x_{n+1}-q\right\|^{2}+D_{3}\left(\mu_{n}+l_{n}\right), \\
& \alpha_{n}\left(1-\alpha_{n}\right) g_{3}\left(\left\|y_{n}-\left(P T_{1}\right)^{n} y_{n}\right\|\right) \leq\left\|x_{n}-q\right\|^{2}-\left\|x_{n+1}-q\right\|^{2}+D_{3}\left(\mu_{n}+l_{n}\right) .
\end{aligned}
$$

Since $0<\liminf _{n \rightarrow \infty} \beta_{n}<\limsup _{n \rightarrow \infty} \beta_{n}<1,0<\liminf _{n \rightarrow \infty} \gamma_{n}<\lim \sup _{n \rightarrow \infty}$ $\gamma_{n}<1$ and $0<\liminf _{n \rightarrow \infty} \gamma_{n}<\limsup _{n \rightarrow \infty} \gamma_{n}<1$, there exist $n_{0} \in \mathbb{N}$ and 
$m_{1}, m_{1}^{*}, m_{2}, m_{2}^{*}, m_{3}, m_{3}^{*} \in(0,1)$ such that $0<m_{1}<\alpha_{n}<m_{1}^{*}, 0<m_{2}<\beta_{n}<m_{2}^{*}$ and $0<m_{3}<\gamma_{n}<m_{3}^{*}$ for all $n \geq n_{0}$. This implies by (2.12) that

$$
m_{3}\left(1-m_{3}^{*}\right) g_{1}\left(\left\|x_{n}-\left(P T_{3}\right)^{n} x_{n}\right\|\right) \leq\left\|x_{n}-q\right\|^{2}-\left\|x_{n+1}-q\right\|^{2}+D_{3}\left(\mu_{n}+l_{n}\right)
$$

for all $n \geq n_{0}$. It follows from (2.15) that $m \geq n_{0}$

$$
\begin{aligned}
\sum_{n=n_{0}}^{m} g_{1}\left(\left\|x_{n}-\left(P T_{3}\right)^{n} x_{n}\right\|\right) \leq & \frac{1}{m_{3}\left(1-m_{3}^{*}\right)}\left(\sum_{n=n_{0}}^{m}\left(\left\|x_{n}-q\right\|^{2}-\left\|x_{n+1}-q\right\|^{2}\right)\right. \\
& \left.+D_{3} \sum_{n=n_{0}}^{m}\left(\mu_{n}+l_{n}\right)\right) \\
\leq & \frac{1}{m_{3}\left(1-m_{3}^{*}\right)}\left(\left\|x_{n_{0}}-q\right\|^{2}+D_{3} \sum_{n=n_{0}}^{m}\left(\mu_{n}+l_{n}\right)\right) .
\end{aligned}
$$

Then $\sum_{n=n_{0}}^{\infty} g_{1}\left(\left\|x_{n}-\left(P T_{3}\right)^{n} x_{n}\right\|\right)<\infty$ and therefore

$$
\lim _{n \rightarrow \infty} g_{1}\left(\left\|x_{n}-\left(P T_{3}\right)^{n} x_{n}\right\|\right)=0 .
$$

Since $g_{1}$ is strictly increasing and continuous with $g_{1}(0)=0$, we have

$$
\lim _{n \rightarrow \infty}\left\|x_{n}-\left(P T_{3}\right)^{n} x_{n}\right\|=0
$$

In a similar way, (2.13) and (2.14) imply

$$
\begin{aligned}
& \lim _{n \rightarrow \infty}\left\|z_{n}-\left(P T_{2}\right)^{n} z_{n}\right\|=0, \\
& \lim _{n \rightarrow \infty}\left\|y_{n}-\left(P T_{1}\right)^{n} y_{n}\right\|=0 .
\end{aligned}
$$

It follows from (1.6) that

$$
\left\|z_{n}-x_{n}\right\| \leq \gamma_{n}\left\|x_{n}-\left(P T_{3}\right)^{n} x_{n}\right\|
$$

Thus by (2.16),

$$
\lim _{n \rightarrow \infty}\left\|z_{n}-x_{n}\right\|=0
$$

Again, from (1.6)

$$
\left\|y_{n}-z_{n}\right\| \leq \beta_{n}\left\|z_{n}-\left(P T_{2}\right)^{n} z_{n}\right\|
$$

so that (2.17) yields $\lim _{n \rightarrow \infty}\left\|y_{n}-z_{n}\right\|=0$. From (2.19) and $\lim _{n \rightarrow \infty}\left\|y_{n}-z_{n}\right\|=$ 0 , we have

$$
\lim _{n \rightarrow \infty}\left\|y_{n}-x_{n}\right\| \leq \lim _{n \rightarrow \infty}\left\|y_{n}-z_{n}\right\|+\lim _{n \rightarrow \infty}\left\|z_{n}-x_{n}\right\|=0
$$

A combined effect of (2.17) and (2.19) yields

$$
\begin{aligned}
\left\|x_{n}-\left(P T_{2}\right)^{n} x_{n}\right\| & \leq\left\|x_{n}-z_{n}\right\|+\left\|z_{n}-\left(P T_{2}\right)^{n} z_{n}\right\|+\left\|\left(P T_{2}\right)^{n} z_{n}-\left(P T_{2}\right)^{n} x_{n}\right\| \\
& \leq 2\left\|x_{n}-z_{n}\right\|+\left\|z_{n}-\left(P T_{2}\right)^{n} z_{n}\right\|+\mu_{n} \phi\left(\left\|z_{n}-x_{n}\right\|\right)+l_{n} .
\end{aligned}
$$

Taking the limit as $n \rightarrow \infty$, we have

$$
\lim _{n \rightarrow \infty}\left\|x_{n}-\left(P T_{2}\right)^{n} x_{n}\right\|=0
$$


Also from

$$
\begin{aligned}
\left\|x_{n}-\left(P T_{1}\right)^{n} x_{n}\right\| & \leq\left\|x_{n}-y_{n}\right\|+\left\|y_{n}-\left(P T_{1}\right)^{n} y_{n}\right\|+\left\|\left(P T_{1}\right)^{n} y_{n}-\left(P T_{1}\right)^{n} x_{n}\right\| \\
& \leq 2\left\|x_{n}-y_{n}\right\|+\left\|y_{n}-\left(P T_{1}\right)^{n} y_{n}\right\|+\mu_{n} \phi\left(\left\|y_{n}-x_{n}\right\|\right)+l_{n},
\end{aligned}
$$

we have

$$
\lim _{n \rightarrow \infty}\left\|x_{n}-\left(P T_{1}\right)^{n} x_{n}\right\|=0
$$

This completes the proof.

Lemma 2.4. Let $K$ be a nonempty closed convex subset of a uniformly convex Banach space $E$ which is also a nonexpansive retract of $E$ and $T_{1}, T_{2}, T_{3}$ : $K \rightarrow E$ be three continuous nonself total asymptotically nonexpansive mappings defined by (1.4) such that $\sum_{n=1}^{\infty} \mu_{n}<\infty, \sum_{n=1}^{\infty} l_{n}<\infty$. Assume that there exist $M, M^{*}>0$ such that $\phi(\lambda) \leq M^{*} \lambda$ for all $\lambda \geq M$. Suppose that $\mathcal{F}$ is singleton and $\left\{\alpha_{n}\right\},\left\{\beta_{n}\right\},\left\{\gamma_{n}\right\}$ are sequences in $[0,1]$ which satisfy the following conditions:

(i) $0<\liminf _{n \rightarrow \infty} \alpha_{n}<\limsup _{n \rightarrow \infty} \alpha_{n}<1$

(ii) $0<\liminf _{n \rightarrow \infty} \beta_{n}<\limsup _{n \rightarrow \infty} \beta_{n}<1$

(iii) $0<\liminf _{n \rightarrow \infty} \gamma_{n}<\limsup _{n \rightarrow \infty} \gamma_{n}<1$.

Then $\lim _{n \rightarrow \infty}\left\|x_{n}-T_{i} x_{n}\right\|=0$ for $i=1,2,3$.

Proof. Note that

$$
\begin{aligned}
\left\|x_{n}-\left(P T_{1}\right)^{n} y_{n}\right\| & \leq\left\|x_{n}-\left(P T_{1}\right)^{n} x_{n}\right\|+\left\|\left(P T_{1}\right)^{n} x_{n}-\left(P T_{1}\right)^{n} y_{n}\right\| \\
& \leq\left\|x_{n}-\left(P T_{1}\right)^{n} x_{n}\right\|+\left\|x_{n}-y_{n}\right\|+\mu_{n} \phi\left(\left\|y_{n}-x_{n}\right\|\right)+l_{n} .
\end{aligned}
$$

Since $T_{1}$ is total asymptotically nonexpansive mapping, (2.20) and (2.22) give

$$
\lim _{n \rightarrow \infty}\left\|x_{n}-\left(P T_{1}\right)^{n} y_{n}\right\|=0
$$

Using (1.6), (2.20) and (2.23), we obtain

$$
\begin{aligned}
\left\|x_{n+1}-x_{n}\right\| & \leq\left\|\left(1-\alpha_{n}\right)\left(y_{n}-x_{n}\right)+\alpha_{n}\left(\left(P T_{1}\right)^{n} y_{n}-x_{n}\right)\right\| \\
& \leq\left(1-\alpha_{n}\right)\left\|y_{n}-x_{n}\right\|+\alpha_{n}\left\|\left(P T_{1}\right)^{n} y_{n}-x_{n}\right\|,
\end{aligned}
$$

so that

$$
\lim _{n \rightarrow \infty}\left\|x_{n+1}-x_{n}\right\|=0
$$

Lemma 2.3 and (2.24) imply

$$
\begin{aligned}
\left\|x_{n}-\left(P T_{i}\right)^{n-1} x_{n}\right\| \leq & \left\|x_{n}-x_{n-1}\right\|+\left\|x_{n-1}-\left(P T_{i}\right)^{n-1} x_{n-1}\right\| \\
& +\left\|\left(P T_{i}\right)^{n-1} x_{n-1}-\left(P T_{i}\right)^{n-1} x_{n}\right\| \\
\leq & 2\left\|x_{n}-x_{n-1}\right\|+\left\|x_{n-1}-\left(P T_{i}\right)^{n-1} x_{n-1}\right\| \\
& +\mu_{n-1} \phi\left(\left\|x_{n}-x_{n-1}\right\|\right)+l_{n-1} .
\end{aligned}
$$

This gives

$$
\lim _{n \rightarrow \infty}\left\|x_{n}-\left(P T_{i}\right)^{n-1} x_{n}\right\|=0 .
$$

Since each $T_{i}$ is continuous and $P$ is nonexpansive retraction, it follows from (2.25) that

$$
\lim _{n \rightarrow \infty}\left\|\left(P T_{i}\right)^{n} x_{n}-T_{i} x_{n}\right\|=\lim _{n \rightarrow \infty}\left\|P T_{i}\left(P T_{i}\right)^{n-1} x_{n}-P T_{i} x_{n}\right\|=0
$$


for $i=1,2,3$.

Hence, by Lemma 2.3 and (2.26), we have

$$
\left\|x_{n}-T_{i} x_{n}\right\| \leq\left\|x_{n}-\left(P T_{i}\right)^{n} x_{n}\right\|+\left\|\left(P T_{i}\right)^{n} x_{n}-T_{i} x_{n}\right\| .
$$

Consequently,

$$
\lim _{n \rightarrow \infty}\left\|x_{n}-T_{i} x_{n}\right\|=0
$$

Theorem 2.5. Let $K$ be a nonempty closed convex subset of a uniformly convex Banach space $E$ which is also a nonexpansive retract of $E$ and $T_{1}, T_{2}, T_{3}: K \rightarrow E$ be three continuous nonself total asymptotically nonexpansive mappings defined by (1.4) such that $\sum_{n=1}^{\infty} \mu_{n}<\infty, \sum_{n=1}^{\infty} l_{n}<\infty$. Assume that there exist $M, M^{*}>0$ such that $\phi(\lambda) \leq M^{*} \lambda$ for all $\lambda \geq M$ and that one of $T_{1}, T_{2}, T_{3}$ is demicompact. Suppose that $\left\{x_{n}\right\}$ is defined by (1.6), $\mathcal{F}$ is singleton and $\left\{\alpha_{n}\right\},\left\{\beta_{n}\right\},\left\{\gamma_{n}\right\}$ are sequences in $[0,1]$ which satisfy the following conditions:

(i) $0<\liminf _{n \rightarrow \infty} \alpha_{n}<\limsup _{n \rightarrow \infty} \alpha_{n}<1$

(ii) $0<\liminf _{n \rightarrow \infty} \beta_{n}<\limsup _{n \rightarrow \infty} \beta_{n}<1$

(iii) $0<\liminf _{n \rightarrow \infty} \gamma_{n}<\limsup _{n \rightarrow \infty} \gamma_{n}<1$.

Then the sequence $\left\{x_{n}\right\}$ converges strongly to a common fixed point of $\left\{T_{i}\right\}_{i=1}^{3}$.

Proof. Without any loss of generality, we may assume that $T_{1}$ is demicompact. From the facts that $\lim _{n \rightarrow \infty}\left\|x_{n}-T_{1} x_{n}\right\|=0$ and $\left\{x_{n}\right\}$ is bounded, there exists a subsequence $\left\{x_{n_{k}}\right\} \subset\left\{x_{n}\right\}$ that converges strongly to some $x^{*} \in K$ as $k \rightarrow \infty$. By Lemma 2.4, $T_{1} x_{n_{k}} \rightarrow x^{*}, T_{2} x_{n_{k}} \rightarrow x^{*}, T_{3} x_{n_{k}} \rightarrow x^{*}$. Continuity of $T_{i}$ gives $T_{i} x_{n_{k}} \rightarrow T_{i} x^{*}$ for all $i=1,2,3$. Now using (2.26), we have

$$
\left\|\left(P T_{i}\right)^{n_{k}} x_{n_{k}}-T_{i} x^{*}\right\| \leq\left\|\left(P T_{i}\right)^{n_{k}} x_{n_{k}}-T_{i} x_{n_{k}}\right\|+\left\|T_{i} x_{n_{k}}-T_{i} x^{*}\right\| .
$$

This implies

$$
\lim _{n \rightarrow \infty}\left\|\left(P T_{i}\right)^{n_{k}} x_{n_{k}}-T_{i} x^{*}\right\|=0 \text { for all } i=1,2,3 .
$$

Observe that

$$
\left\|x^{*}-T_{1} x^{*}\right\| \leq\left\|x^{*}-x_{n_{k}}\right\|+\left\|x_{n_{k}}-\left(P T_{1}\right)^{n_{k}} x_{n_{k}}\right\|+\left\|\left(P T_{1}\right)^{n_{k}} x_{n_{k}}-T_{1} x^{*}\right\| .
$$

Using (2.28) and Lemma 2.3, we get $T_{1} x^{*}=x^{*}$ and so $x^{*} \in F\left(T_{1}\right)$.

To prove $x^{*} \in F\left(T_{2}\right)$, note that

$$
\left\|x^{*}-T_{2} x^{*}\right\| \leq\left\|x^{*}-x_{n_{k}}\right\|+\left\|x_{n_{k}}-\left(P T_{2}\right)^{n_{k}} x_{n_{k}}\right\|+\left\|\left(P T_{2}\right)^{n_{k}} x_{n_{k}}-T_{2} x^{*}\right\| .
$$

We can similarly say that $x^{*} \in F\left(T_{3}\right)$. Therefore, $x^{*} \in \mathcal{F}$. According to Lemma 2.1, the $\operatorname{limit} \lim _{n \rightarrow \infty}\left\|x_{n}-x^{*}\right\|$ exists. Hence $\lim _{n \rightarrow \infty} x_{n_{k}}=x^{*} \in \mathcal{F}$. This completes the proof.

Corollary 2.6. Let $K$ be a nonempty closed convex subset of a uniformly convex Banach space $E$ which is also a nonexpansive retract of $E$ and $T_{1}, T_{2}, T_{3}: K \rightarrow E$ be three continuous nonself total asymptotically nonexpansive mappings defined by (1.4) such that $\sum_{n=1}^{\infty} \mu_{n}<\infty, \sum_{n=1}^{\infty} l_{n}<\infty$ and $T_{1}, T_{2}, T_{3}$ are satisfying the condition $(B)$. Assume that there exist $M, M^{*}>0$ such that $\phi(\lambda) \leq M^{*} \lambda$ for all $\lambda \geq M$. Suppose that $\left\{x_{n}\right\}$ is defined by (1.6), $\mathcal{F}$ is singleton and $\left\{\alpha_{n}\right\},\left\{\beta_{n}\right\},\left\{\gamma_{n}\right\}$ are sequences in $[0,1]$ which satisfy the following conditions: 
(i) $0<\liminf _{n \rightarrow \infty} \alpha_{n}<\limsup _{n \rightarrow \infty} \alpha_{n}<1$

(ii) $0<\liminf _{n \rightarrow \infty} \beta_{n}<\limsup _{n \rightarrow \infty} \beta_{n}<1$

(iii) $0<\liminf _{n \rightarrow \infty} \gamma_{n}<\lim \sup _{n \rightarrow \infty} \gamma_{n}<1$.

Then the sequence $\left\{x_{n}\right\}$ converges strongly to a common fixed points of $\left\{T_{i}\right\}_{i=1}^{3}$.

Proof. By Lemma 2.4, $\lim _{n \rightarrow \infty}\left\|x_{n}-T_{i} x_{n}\right\|=0$ for $i=1,2,3$. Since $T_{1}, T_{2}, T_{3}$ satisfy the condition $(B), f\left(d\left(x_{n}, \mathcal{F}\right)\right) \leq \max _{1 \leq i \leq 3}\left\{\left\|x_{n}-T_{i} x_{n}\right\|\right\}$. Thus $\lim _{n \rightarrow \infty}$ $f\left(d\left(x_{n}, \mathcal{F}\right)\right)=0$. Since $f$ is a nondecreasing function and $f(0)=0$, therefore $\lim _{n \rightarrow \infty} d\left(x_{n}, \mathcal{F}\right)=0$. The rest of the proof follows as in proof of Theorem 2.2 .

Theorem 2.7. Let $K$ be a nonempty closed convex subset of a uniformly convex Banach space E satisfying Opial's condition which is also a nonexpansive retract of $E$ and $T_{1}, T_{2}, T_{3}: K \rightarrow E$ be three continuous nonself total asymptotically nonexpansive mappings defined by (1.4) such that $\sum_{n=1}^{\infty} \mu_{n}<\infty, \sum_{n=1}^{\infty} l_{n}<\infty$. Assume that there exist $M, M^{*}>0$ such that $\phi(\lambda) \leq M^{*} \lambda$ for all $\lambda \geq M$. Suppose that $\left\{x_{n}\right\}$ is defined by (1.6), $\mathcal{F}$ is singleton and $\left\{\alpha_{n}\right\},\left\{\beta_{n}\right\},\left\{\gamma_{n}\right\}$ are sequences in $[0,1]$ which satisfy the following conditions:

(i) $0<\liminf _{n \rightarrow \infty} \alpha_{n}<\limsup _{n \rightarrow \infty} \alpha_{n}<1$

(ii) $0<\liminf _{n \rightarrow \infty} \beta_{n}<\limsup _{n \rightarrow \infty} \beta_{n}<1$

(iii) $0<\liminf _{n \rightarrow \infty} \gamma_{n}<\limsup _{n \rightarrow \infty} \gamma_{n}<1$.

If the mappings $I-T_{i}(i=1,2,3)$ are semiclosed at zero, then the sequence $\left\{x_{n}\right\}$ converges weakly to a common fixed points of $\left\{T_{i}\right\}_{i=1}^{3}$.

Proof. Let $q_{1} \in \mathcal{F}$. By Lemma 2.1, $\lim _{n \rightarrow \infty}\left\|x_{n}-q_{1}\right\|$ exists and $\left\{x_{n}\right\}$ is bounded. Since $E$ is uniformly convex, every bounded subset of $E$ is weakly compact. Since $\left\{x_{n}\right\}$ is a bounded sequence in $K$, there exists a subsequence $\left\{x_{n_{k}}\right\} \subset\left\{x_{n}\right\}$ such that $\left\{x_{n_{k}}\right\}$ converges weakly to $q_{1} \in K$. Using Lemma 2.4, we have

$$
\lim _{n \rightarrow \infty}\left\|x_{n_{k}}-T_{i} x_{n_{k}}\right\|=0
$$

for $i=1,2,3$. Since the mappings $I-T_{i}(i=1,2,3)$ are semiclosed at zero, therefore, we have $T_{i} q_{1}=q_{1}$. That is, $q_{1} \in \mathcal{F}$.

Finally, let us prove that $\left\{x_{n}\right\}$ converges weakly to $q_{1}$. Suppose on contrary that there exists a subsequence $\left\{x_{n_{j}}\right\} \subset\left\{x_{n}\right\}$ such that $\left\{x_{n_{j}}\right\}$ converges weakly to $q_{2} \in K$ and $q_{1} \neq q_{2}$. Then by the same method as given above, we can also prove that $q_{2} \in \mathcal{F}$. Since $q_{1}, q_{2} \in \mathcal{F}$, according to Lemma $2.1 \lim _{n \rightarrow \infty}\left\|x_{n}-q_{1}\right\|$ and $\lim _{n \rightarrow \infty}\left\|x_{n}-q_{2}\right\|$ exist, and we have

$$
\lim _{n \rightarrow \infty}\left\|x_{n}-q_{1}\right\|=r_{1}, \quad \lim _{n \rightarrow \infty}\left\|x_{n}-q_{2}\right\|=r_{2},
$$

where $r_{1}, r_{2} \geq 0$. Because of the Opial's condition of $E$, we obtain

$$
\begin{aligned}
r_{1} & =\lim _{n_{k} \rightarrow \infty} \sup \left\|x_{n_{k}}-q_{1}\right\|<\lim _{n_{k} \rightarrow \infty} \sup \left\|x_{n_{k}}-q_{2}\right\|=r_{2} \\
\text { and } r_{2} & =\lim _{n_{j} \rightarrow \infty} \sup \left\|x_{n_{j}}-q_{2}\right\|<\lim _{n_{j} \rightarrow \infty} \sup \left\|x_{n_{j}}-q_{1}\right\|=r_{1} .
\end{aligned}
$$

This is a contradiction. Hence $q_{1}=q_{2}$. This implies that $\left\{x_{n}\right\}$ converges weakly to $q_{1}$. This completes the proof. 


\section{REFERENCES}

1. Y.I. Alber, C.E. Chidume and H. Zegeye, Approximating fixed points of total asymptotically nonexpansive mappings, Hind. Publis. Corp. Fixed Point Theory Appl., Article ID 10673 (2006), 1-20.

2. C.E. Chidume and E.U. Ofoedu, Approximation of common fixed points for finite families of total asymptotically nonexpansive mappings, J. Math. Anal. Appl. 333 (2007), 128-141.

3. C.E. Chidume, E.U, Ofoedu and H. Zegeye, Strong and weak convergence theorems for asymptotically nonexpansive mappings, J. Math. Anal. Appl. 280 (2003), 364-374.

4. K. Goebel and W.A. Kirk, A fixed point theorem for asymptotically nonexpansive mappings, Proc. Amer. Math. Soc. 35 (1972), 171-174.

5. G. Hu and L. Yang, Strong convergence of the modified three step iterative process in Banach spaces, Dyn. Contin. Discrete Impuls. Syst. Ser. A Math. Anal. 15 (2008), 555-571.

6. S.H. Khan and N. Hussain, Convergence theorems for nonself asymptotically nonexpansive mappings, Comp. Math. App. 55 (2008), 2544-2553.

7. E. Lami Dozo, Multivalued nonexpansive mappings and Opial's condition, Proc. Amer. Math. Soc. 38 (1973), 286-292.

8. F. Mukhamedov and M. Saburov, Strong Convergence of an Explicit Iteration Process for a Totally Asymptotically I-Nonexpansive Mapping in Banach Spaces, Appl. Math. Lett. (2010), 1473-1478.

9. R.A. Rashwan and S.M. Altwqi, Convergence theorems for common fixed points of nonself asymptotically nonexpansive mappings, Int. J. Pure Appl. Math. 70 (2011), 503-520.

10. K.K. Tan and H.K. Xu, Approximating fixed points of nonexpansive mappings by the Ishikawa iteration process, J. Math. Anal. Appl. 178 (1993), 301-308.

11. S. Thianwan, Common fixed point of new iterations for two asymptotically nonexpansive nonself mappings in a Banach space, J. Comput. Appl. Math. 224 (2009), 688-695.

12. Z. Opial, Weak convergence of the sequence of successive approximations for nonexpansive mappings, Bull. Amer. Math. Soc. 73 (1967), 591-597.

13. H.K. Xu, Inequalities in Banach spaces with applications, Nonlinear Anal. 16 (1991), 11271138.

${ }^{1}$ Department of Mathematics, Statistics and Physics, Qatar University, Doha 2713, QATAR.

E-mail address: safeer@qu.edu.qa

${ }^{2}$ Department of Mathematics, Faculty of Science, Ataturk University, ErzuRUM, 25240, TURKEY.

E-mail address: hukmu@atauni.edu.tr

3 Celal Bayar University, Manisa, 45450, Turkey.

E-mail address: yunus.purtas@cbu.edu.tr 